\title{
Assessment of Rainfall, Streamflow and Reservoir Level Trends for Malewa River Catchment, Naivasha, Kenya
}

\author{
Elizabeth Wambui Nyokabi", Raphael Muli Wambua, Romulus Okoth Okwany \\ Department of Agricultural Engineering, Egerton University, Nakuru, Kenya
}

Email address:

nyokabiwambui@gmail.com (E. W. Nyokabi)

${ }^{*}$ Corresponding author

\section{To cite this article:}

Elizabeth Wambui Nyokabi, Raphael Muli Wambua, Romulus Okoth Okwany. Assessment of Rainfall, Streamflow and Reservoir Level Trends for Malewa River Catchment, Naivasha, Kenya. Journal of Civil, Construction and Environmental Engineering.

Vol. 6, No. 1, 2021, pp. 1-8. doi: 10.11648/j.jccee.20210601.11

Received: December 19, 2020; Accepted: December 28, 2020; Published: January 12, 2021

\begin{abstract}
Appropriate water quality and quantity are critical problem greatly affecting significant proportion of the population particularly those living in semi-arid and arid areas. Rainfall characteristics, streamflow and reservoir levels are some of the key hydro-meteorological variables within a catchment in the determination of sufficiency of water quantity. Lake Naivasha reservoir level continues to be hit by anthropogenic stressors such as loss of wetlands, water abstraction and eutrophication. Also there has been a lot of fluctuation in flow discharge of Malewa River over the years where the tributaries (Turasha and Karati streams) usually dries up during dry season. This paper presents the results of a research to assess the time series trends of rainfall, streamflow and lake basin levels data in the catchment from 1980-2018 using Mann-Kendall trend test to assess water quantity status. Monthly stream flow, rainfall and reservoir level data in the catchment were obtained from Water Resources Management Authority (WRMA) and Kenya Meteorological Department (KMD) for the years 1980-2018. Non-parametric Mann-Kendall rank statistics test was used to examine the trend components of hydro-meteorological variables. The P-values were used to test whether the null hypotheses were statistically significant $(\alpha<0.05)$ at a $\%$ level of significance. Rainfall values had an increasing trend from 2011 onwards but not statistically significant while annual streamflow values had no trend as P-value showed weak evidences to rejected the null hypothesis. Reservoir level had an upward trend in years 1981, 2001, 2003, 2012 and 2018 while downward trends in 1980, 1982, 1984, 1986, 1987, 2000, 2004, 2008 and 2014. From 2010 onwards, in monthly data, there have been upward water levels in the lake as shown by the trend. These show that the hydro-meteorological indicators in the catchment are independently trending, therefore some other factors such as land cover changes or climate changes were adversely affecting the hydrological cycle. These findings are helpful for planning and management in water resource systems such as forecasting water distribution and mitigate flood and drought.
\end{abstract}

Keywords: Rainfall, Reservoir Level, River Malewa, Streamflow, Trends of Hydro-meteorological Data

\section{Introduction}

Climate change, climate variability and global warming are the most significant issues facing the world today since they alter climate patterns and increase the frequency of extreme weather events. Frequent occurrence of extreme climate events such as flood and drought has become a global concern [1]. Therefore, climate, hydrological parameters and characteristics of water resource systems affects and influences water resources making management practices difficult to undertake. Changes in hydro-meteorological data such as rainfall, streamflow and temperatures critically affects the various forms of water resources events such as floods and droughts [2]. One of the biggest hazard in environmental management is water scarcity [3]. To understand the impacts of climate change on water bodies such as lakes or catchments, necessary measures such as statistical testing should be done.

Quality and quantity of water in Lake Naivasha have been affected in a destructive way such as eutrophication, water abstraction, swelling of the Lake caused by siltation and loss of its wetland over the years [4]. Similarly, Malewa River flow fluctuation has also been noted to be a result of land degradation and climate change [5]. Lake Naivasha, the third 
largest lake in Kenya, is fed by main two rivers, Malewa and Gilgil Rivers, where Malewa River is the major discharge to the lake with about $90 \%$ [6-8]. However, the catchment area is highly affected by lack of water (less than 1000m3/day/capita) [9], developing hydrological drought causing high rise in poverty level, hunger, insecurity crises, water scarcity and degradation of socio-economic projects.

The main variables affecting climate or weather includes rainfall, streamflow, temperature, relative humidity, wind and reservoir levels. Mann- Kendall (MK) test, a non-parametric rank-based method which does not require the normal distribution of data, has been identified as an appropriate statistical test to evaluate these hydro-meteorological variables. This test is most appropriate for the analysis of time series hydro-meteorological data as it shows a significant trend and detect climate discontinuity [10]. This method is statistical and therefore it can be used in studying spatial variation and temporal trends of hydro-climatic series [11]. Mann-Kendall (MK) trend test was used to show occurrence of drought where there was an increasing of drought trend in South-Eastern parts and no trend in north-western areas of Upper Tana River Basin, Kenya [12].

Mann-Kendall (MK) trend test has been used successfully in trend detection of time series data sets. Mann-Kendall trend test was used to analyses the trend of mean temperature data in Catalcakocaeli Peninsula, Northwest of Turkey from 1970 to 2011 and found out that the trend started from the early 1990s because of the population growth and the urbanization effect in the area [13]. It was also used to analyze changes in precipitation and drought in Aksu River Basin, Northwest China and the result showed that precipitation in upstream of Aksu Basin is larger than that in Downstream [14]. MK tests analyzed time series annual mean temperature from 1970-2011 to determine the trends and abrupt changes over the years and the warming effect [13]. It was found out that, the trend in annual mean temperatures was significant at the $95 \%$ statistical confidence level and the trend started from 1990s because of the population growth and urbanization effect. However, the Mann-Kendall test is not able to provide an estimate of trend magnitude and thus other approaches such as Theil-Sen is commonly used for quantifying the magnitude of the trend.

The basic principle of Mann-Kendall test for detecting trends in time series are to examine the sign of all pair wise differences of observed values for monotonic upward or downward trend of the variable of interest over a given time. Assessing the trends of hydro-meteorological variables facilitates accurate water resource forecasting, particularly for those living in arid and semiarid regions where there is high evaporation and low rainfall volume [15]. This is because time series have a skewed or non-normal distribution hence more suitable for use in non-parametric methods than parametric methods for trend detection [2].

The strength of the trend depends on data series' magnitude, variation and sample size. The Mann-Kendall test, $\mathrm{S}$, when testing the statistics and become positive, then observation obtained later in time series tend to be larger than the observation made earlier and when $\mathrm{S}$ are negative values, then observation made later in time tend to be smaller than the observation made earlier [16]. P-value is a probability score that is used in statistical tests to establish the statistical significance of an observed effect assuming the null hypothesis is correct. The smaller the P-value, the stronger the evidence in favour of the alternative hypothesis. The P-value approach for hypothesis testing uses the calculated probability to determine whether there is evidence to reject the null hypothesis obtained from Unit Normal Z table.

Time series trend of rainfall, streamflow and Lake basin levels has not been adequately studied in Malewa catchment that drain into Lake Naivasha. This paper therefore presents results of the study that assessed the trend of these time series data using Mann-Kendall trend test with a view to providing sound water resources management strategy for the catchment.

\section{Materials and Methods}

\subsection{Description of Study Area}

Malewa River catchment is located in Naivasha Basin within Nakuru County in Kenya a shown in Figure 1. It lies within the central Rift Valley of Kenya between latitudes $0^{\circ} 10^{\prime}$ $\mathrm{S}$ to $1^{\circ} 00^{\prime} \mathrm{S}$ and longitudes $36^{\circ} 10^{\prime} \mathrm{E}$ to $36^{\circ} 40^{\prime} \mathrm{E}$, with UTM zone 37 south. The catchment of Malewa River is approximately $1760 \mathrm{~km}^{2}$ [5]. The highest altitude is on the eastern side of the Aberdare ranges of about $3990 \mathrm{~m}$ above sea level (a.m.s.l), while the lowest altitude is of about $1900 \mathrm{~m}$ (a.m.s.l) [17] near the Lake, Eastern Rift Valley.

The catchment has two rainy seasons which are influenced by local relief; Aberdare Mountain to the East and Mau Escarpment to the west. The long rains occur between March and May and short rain between October and November. Its average annual rainfall is $1525 \mathrm{~mm}$ per annum in Aberdare ranges and $610 \mathrm{~mm}$ per annum in Lake Naivasha basin [17]. The daily average temperature ranges from 8 to $30^{\circ} \mathrm{C}$ and its annual potential evaporation is approximately $1700 \mathrm{~mm}$.

Malewa River rises in the western slopes of the Aberdare range in Kenya and flows south and west to Lake Naivasha. The main tributaries are namely; Wanjohi, Turasha, Simba, Nyairoko and O1 Kalou. Malewa River contributes about 90\% of the total discharge into Lake Naivasha [17]. Ground water discharge from the weathered volcanic aquifers provides base flow to the river.

The key hydro-meteorological data collected from 1980 to 2018 are: rainfall of Malewa River catchment, streamflow of Malewa River and reservoir level of Lake Naivasha. The monthly rainfall data and daily streamflow and reservoir level were obtained from Kenya Meteorological Department (KMD) and Water Resources Management Authority (WRMA) respectively.

\subsection{Trend Analysis of Hydro-meteorological Indicators}

Mann-Kendall statistics was used to determine the trend analysis of the time series of rainfall and streamflow in Malewa River catchment and reservoir level of Lake Naivasha. 
The Mann-Kendall test statistics, S, was calculated by programming it in Matlab. Using a two-tailed trend technique, it was employed to test the hypothesis at 5\% significant level where $\mathrm{H} 0$ meant no trend of time series in statistical significant and Ha meant there was trend in time series at 5\% statistical significant. The mathematical ways are as shown in Equations (1), (2), (3), (4) and (5) below.

$$
S=\sum_{i=1}^{n-1} \sum_{j=i+1}^{n} \operatorname{sgn}\left(x_{j}-x_{i}\right)
$$

where,

$\mathrm{n}=$ number of data points

$x i$ and $x j=$ data values in time series $i$ and $j(j>i)$, respectively $\operatorname{sgn}(x i-x j)=\operatorname{sign}$ function which is determined as

$$
\operatorname{sgn}\left(\mathrm{x}_{\mathrm{j}}-\mathrm{x}_{\mathrm{i}}\right)=\left\{\begin{array}{l}
+1, \text { if } x_{j}-x_{i}>0 \\
0, \text { if } x_{j}-x_{i}=0 \\
-1, \text { if } x_{j}-x_{i}<0
\end{array}\right.
$$

Equation (3) is used to calculate mean and variance where sample size, $n$, is greater than 10 .

$$
\begin{gathered}
\mu(\mathrm{S})=0, \\
\sigma^{2}(S)=\frac{n(n-1)(2 n+5)-\sum_{i=1}^{m} t_{i}\left(t_{i}-1\right)\left(2 t_{i}+5\right)}{18}
\end{gathered}
$$

Where $m$ are the numbers of tied groups and $t_{i}$ denotes the number of ties of extent $i$.

In the absence of ties between the observations, the variance is computes as equation (4);

$$
\sigma^{2}(S)=\frac{n(n-1)(2 n+5)}{18}
$$

The standard normalized test statistics $Z_{\mathrm{s}}$ was computed as;

$$
Z_{s}=\left\{\begin{array}{l}
\frac{s-1}{\sqrt{\sigma^{2}(S)}}, \text { if } S>0 \\
0, \text { if } S=0 \\
\frac{S+1}{\sqrt{\sigma^{2}(S)}}, \text { if } S<0
\end{array}\right.
$$

Positive values of $Z$ s indicated an increasing trend while the negative Zs showed decreasing trends. The trend was also verified using a specific significant level $(\alpha)$. P-value was used to test whether the calculated Z-test is hypothetically correct or should be rejected. Attaining a smaller p-value showed that there is a stronger evidence in favour of the alternative hypothesis. P-value used the calculated probability to determine whether there was evidence to reject the null hypothesis. If the P-value was less than the chosen $\alpha=0.05$ then the null hypothesis would be rejected and accepted the alternative hypothesis. Two-tailed test was used in determined the trend of the hydro-meteorological data.

The Mann-Kendall trend test was summarized in the shown flow chart (Figure 2).

\section{Results and Discussion}

\subsection{Trend in Rainfall}

The results of the Mann-Kendall trend test for annual and monthly rainfall in Malewa catchment is as shown in Figure 3 where $\mathrm{Z}$ and $\mathrm{P}$ values are clearly shown on the ordinate scale. There were increasing and decreasing trends as indicated by Z-values and from 2011 onward there were increasing trends but were not statistically significant at 5\% level except 1998 and 2010 which indicated a downward trend using p-values.

The results of trend for monthly rainfall also showed that there was no trend except in September where there was an increasing trend from 1980 to 2018 using significant level (5\%). These results are generally consistent with Mohammed et al. [1] where there was an increase of rainfall in September, though contradictory with Mwenda, [18]. Table 1 and Figure 4 shows the Z-value and $\mathrm{P}$-values of all the months under specified period of this study.

Table 1. Monthly $Z$ and $P$ values for 39 years.

\begin{tabular}{llll}
\hline Mann Kendall & Z-Value & P-Value & Trends (Z-values) \\
\hline Jan & 0.9814 & 0.32640 & Increasing \\
Feb & -0.1188 & 0.90528 & Decreasing \\
Mar & 1.5121 & 0.13051 & Increasing \\
Apr & 0.2634 & 0.79224 & Increasing \\
May & 0.4828 & 0.62924 & Increasing \\
Jun & -0.2130 & 0.83133 & Decreasing \\
Jul & 1.0509 & 0.29331 & Increasing \\
Aug & 0.9373 & 0.34860 & Increasing \\
Sep & 2.9013 & 0.00372 & Increasing \\
Oct & 1.0674 & 0.28579 & Increasing \\
Nov & -0.1988 & 0.84226 & Decreasing \\
Dec & 0.2075 & 0.83562 & Increasing \\
\hline
\end{tabular}

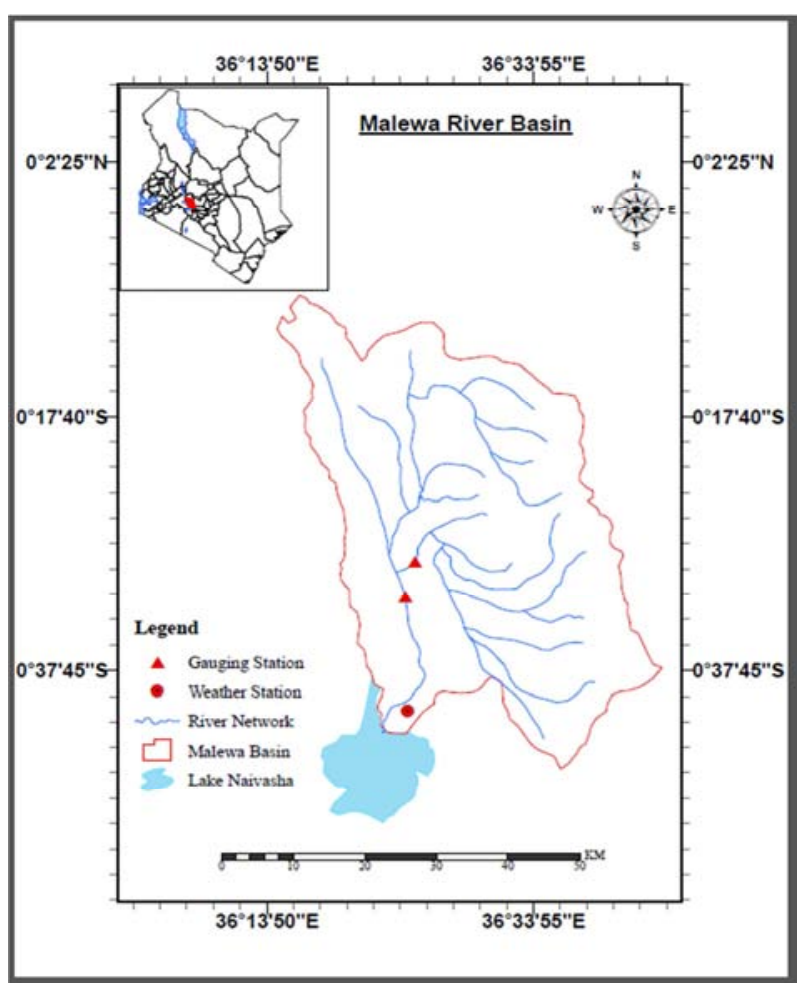

Figure 1. Map of Malewa River Basin. 


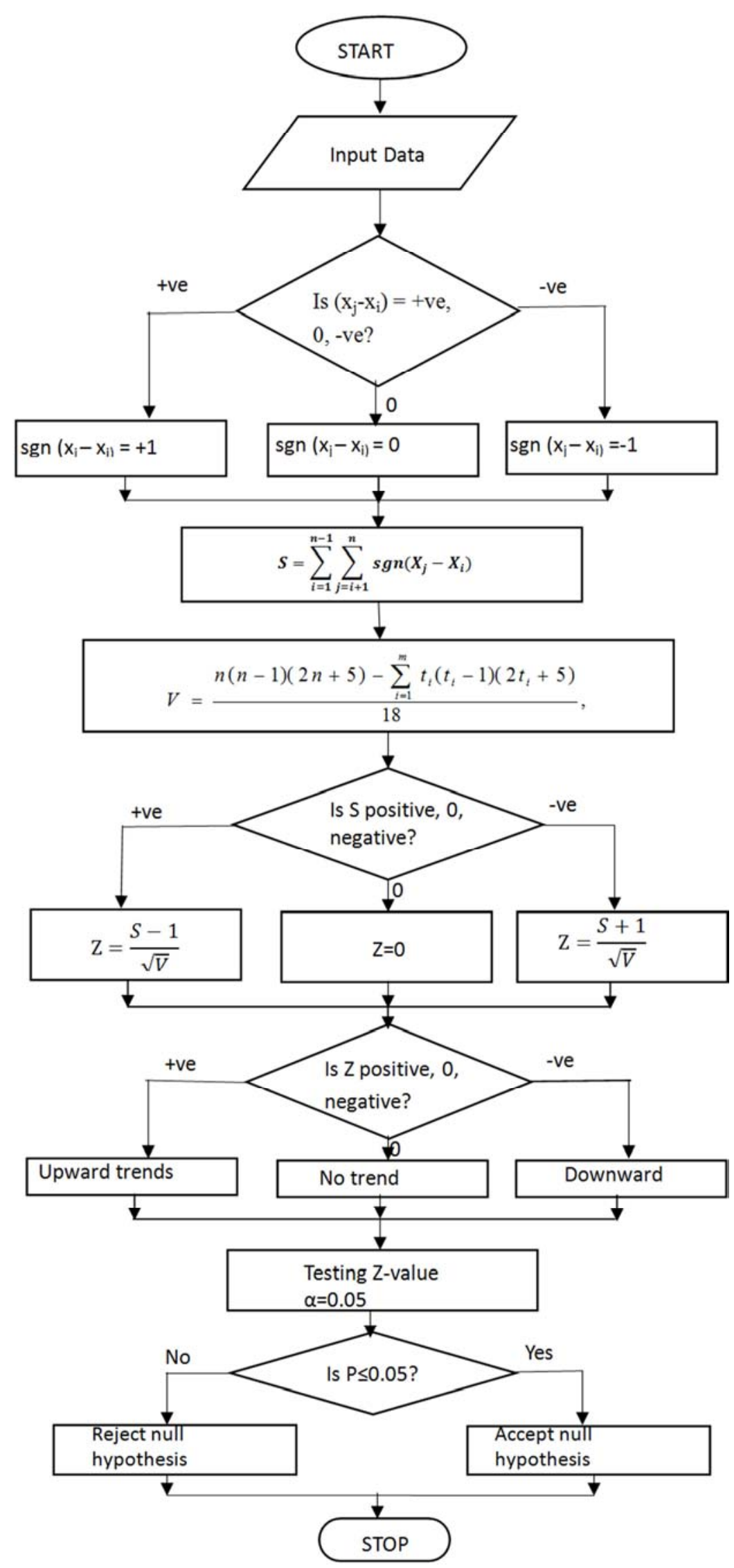

Figure 2. Flow Chart of Mann-Kendall test. 


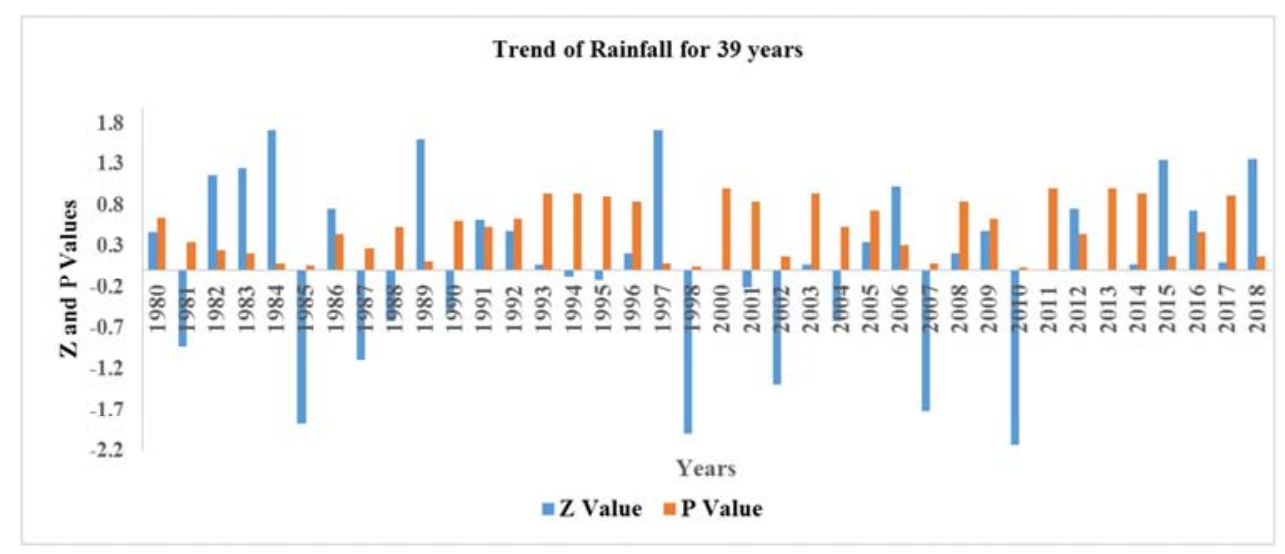

Figure 3. Trend of Rainfall for 39 years.

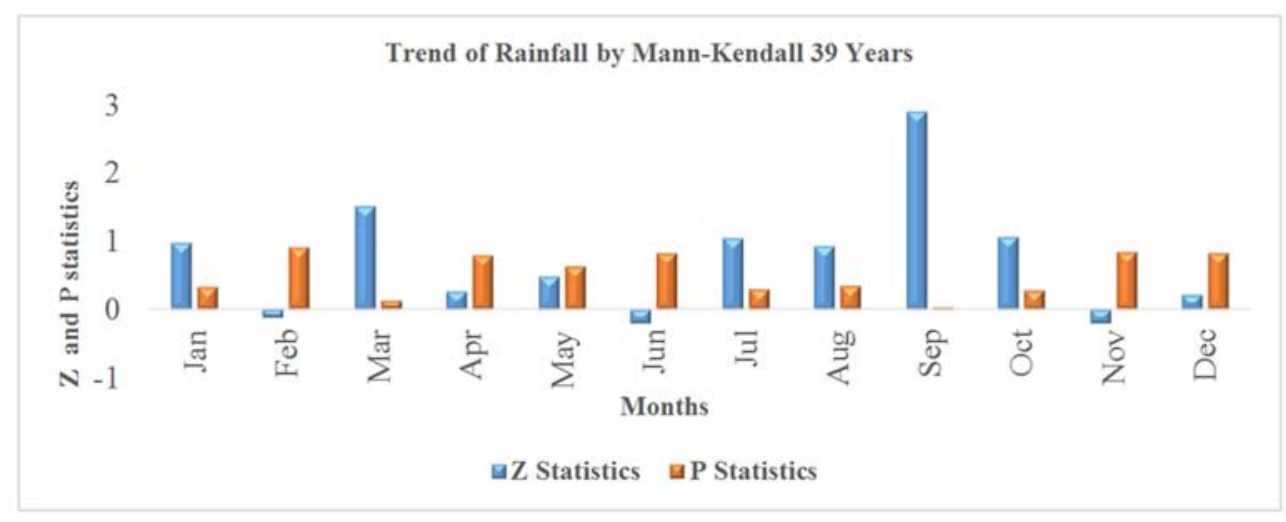

Figure 4. Trend of Rainfall in months for 39 years.

When there are no trends, the observed data obtained over time (years or months) were independently and identically distributed. Therefore, no general trend of rainfall for the previous periods [19].

\subsection{Trend of Streamflow}

In determining the trends of streamflow, both the two gauging stations, Malewa (2GB05) and Turasha (2GC04), showed that there were no trends in annual streamflow discharge for all the years when programmed in Matlab. These results correlate with the study of Cheruiyot et al. [5]. The statistical significant P-value associated with Mann Kendall test suggests that there was a weak evidence to reject the null hypothesis since the P-values were higher than $\alpha=0.05$.

However, the monthly data for each year were programmed in Matlab to determine the trend of each year from 1980 to 2018 and Figure 5 shows the $Z$ and $P$ values. Using $Z$-values, most of the years had an upward trend. Nevertheless, the Pvalue test evidently showed increasing trend in 1982, 2006, 2008, 2009, 2011, 2014 and 2015 and a decreasing trend in 1993.

The streamflow trend was also determined in monthly arrangement for 39 years, as shown in Figure 6. There was a decreasing trend in September and October at Turasha gauging station (2GC04) and February at Malewa gauging station (2GB05).

\subsection{Trend of Reservoir Level}

The reservoir level trends were determined using Mann-Kendall tests programmed in Matlab where most of the years showed either upward or downward trends as shown in Figure 7. The years 1981, 2001, 2003, 2012 and 2018 indicated an increasing trend while 1980, 1982, 1984, 1986, 1987, 2000, 2004, 2008 and 2014 showed a decreasing trend as the results were statistically significant using P-values. As shown by the graph, the reservoir level regularly had a downward trend up to 2008 which closely matches the finding presented by Odongo., Reta., Awange., Boitt [19-22]. However, the water level in the Lake from 2009 had an upward trend except 2014 and 2017 as shown in Figure 7.

The trends of monthly reservoir levels from 1980 to 2018 showed that there were downward trends but were not statistically significance except the month of June and July using P-values. The monthly trends of reservoir level are shown in Figure 8. However, with the rising water level in the recent years, the monthly trends of water level from 2010 to 2018 indicated an upwards trend as shown in Figure 9 but only September and October were statistically significant using P-values. Therefore, the yearly and monthly trend results are similar from 2010 to 2018 expect 2014 and 2017 which had a downward trend. The Eastern Rift valley lakes in Kenya have been having an extraordinary lake level change from the year 2011 onward [9]. From 2011, the were increasing trends of rainfall which could be the cause of rising water level in Lake Naivasha. 


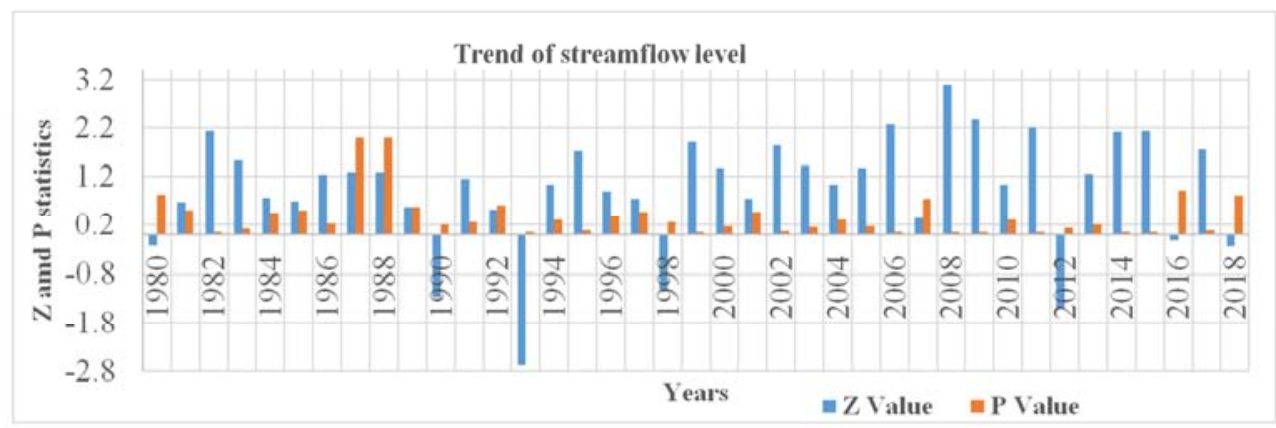

Figure 5. Trend Analysis of streamflow for 39 years.

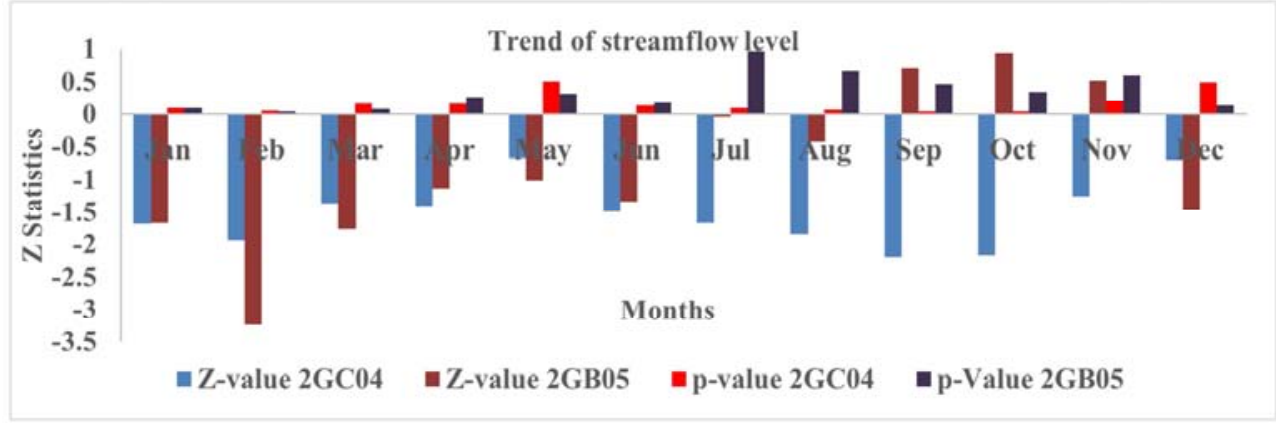

Figure 6. Trend of total streamflow.

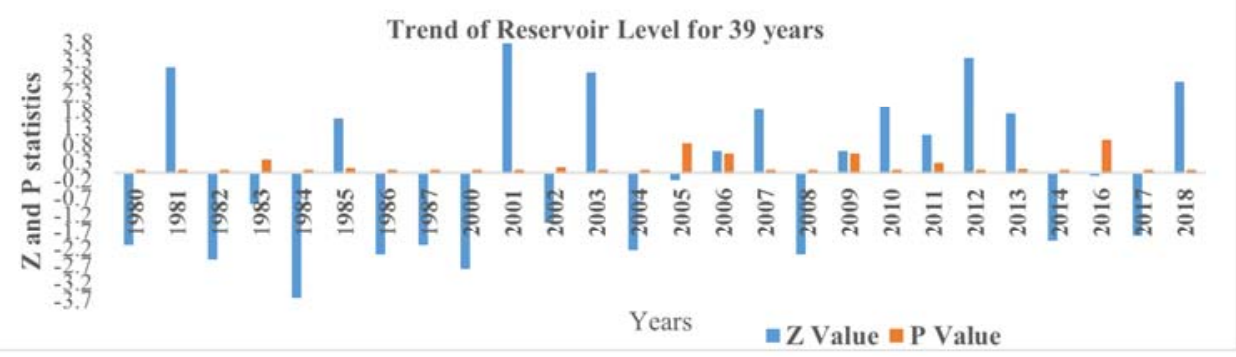

Figure 7. Trend of Reservoir level for 39 years.

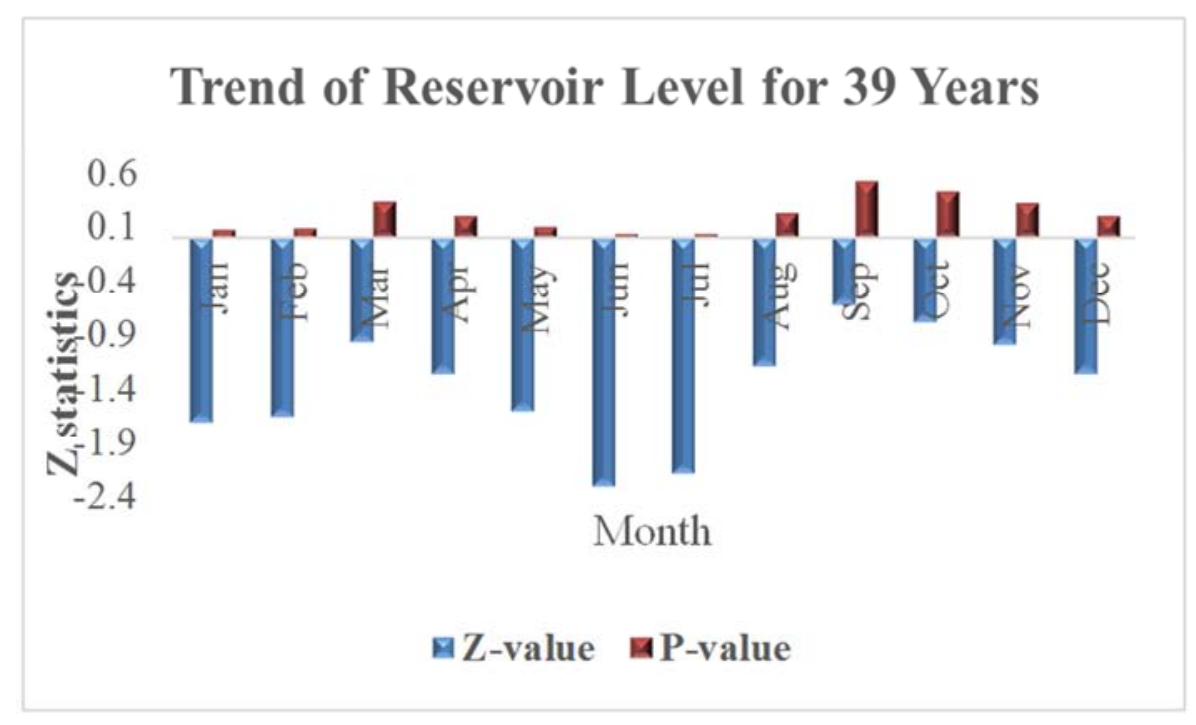

Figure 8. Trend analysis for Reservoir level in months. 


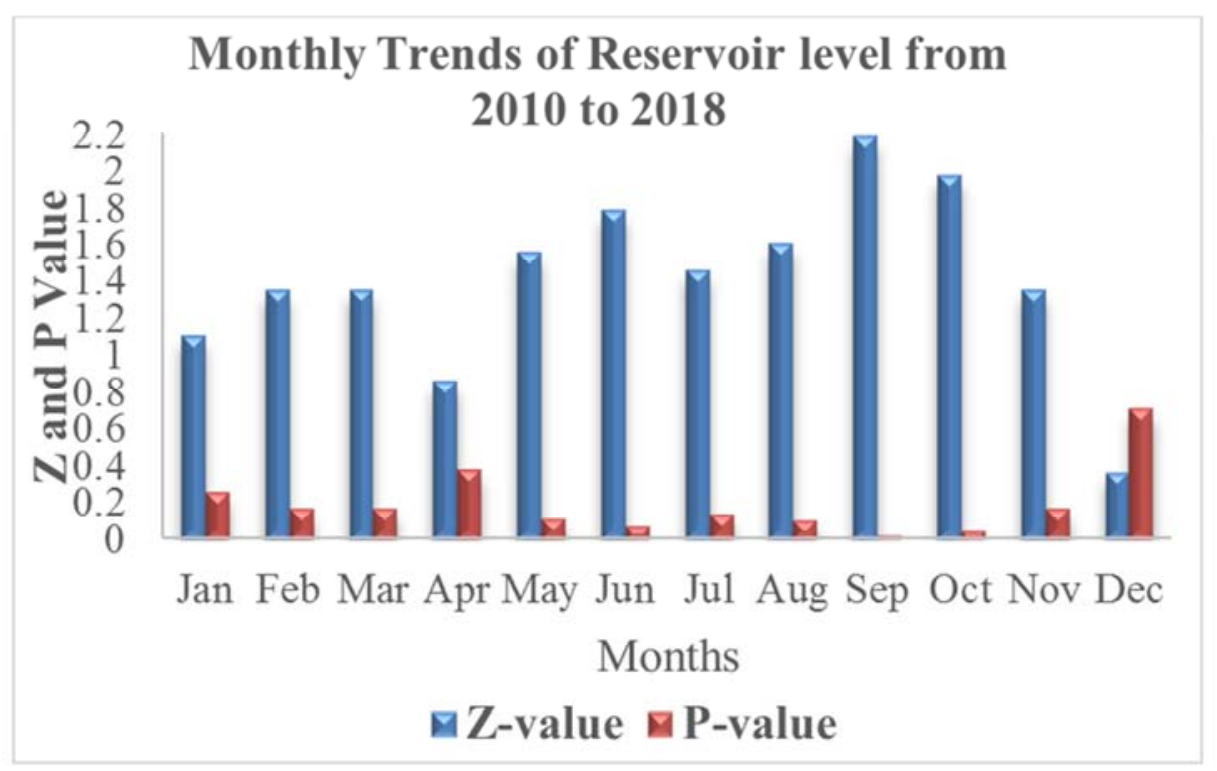

Figure 9. Monthly Trend Analysis for Reservoir Level from 2010 to 2018.

\section{Conclusion}

The hydro-meteorological data obtained from Malewa River catchment shows that the variables had both increasing and decreasing trends but most of them were not statistically significant at 5\% significant level. The variables didn't also show any relationships for the period under study except for rainfall and reservoir level that showed relationship for the years after 2011. Rainfall data trends were contradicting with streamflow data trends since the yearly or monthly trends didn't have any relationship therefore indicating that other factors were greatly influencing these indicators. As indicated by Cheruiyot et al. [5], Malewa River was likely experiencing effects of extreme climate conditions that why there was a lot of fluctuation in the streamflow. Rainfall trends could also be changing depending on climate changes and global warming where the seasonality of rainfall volume changes affects those who depend on it like farmers, power generation and water resources. The upwards and downwards trends of the variables may prompt future severe drought in the catchment and therefore more attention should be emphasized on climate change and water resources management. Also having no relationship of the variables, anthropogenic activates such as land use changes and groundwater overexploitation could affect streamflow discharge, therefore should have more attention.

\section{Acknowledgements}

Authors would like to sincerely thank the Water Resource Management Authority (WRMA) in Naivasha and Kenya Meteorological Department (KMD) for providing secondary data and Center of Excellence in Sustainable Agriculture and Agribusiness Management (CESAAM) and Faculty of Engineering and Technology for their supports.

\section{References}

[1] Mohammed, G., Denghua, Y., Hao, W., Tianling, Q., Abel, G., Asaminew, A., \& Dorjsuren, B. (2018). Innovative Trend Analysis of Annual and Seasonal Rainfall Variability in Amhara Regional State, Ethiopia. Atmosphere, 9 (326). https://doi.org/10.3390/atmos9090326.

[2] Tosunoglu, F. (2017). Trend Analysis of Daily Maximum Rainfall Series in Coruh Basin, Coruh Havza' sındaki Günlük Maksimum Yağış Serilerinin Trend Analizi. Iğdır Univ. J. Inst. Sci. \& Tech., 7 (1), 195-205.

[3] Rakonczai, J. (2011). Effects and consequences of global climate change in the Carpathian Basin. In J. Blanco \& H. Kheradmad (Eds.), Climate change- Geophysical foundations and ecological affects (Climate ch, pp. 229-232). Intech, Rijeka.

[4] Njiru, J., Waithaka, E., \& Aloo, P. A. (2017). An Overview of the Current Status of Lake Naivasha Fishery: Challenges and Management Strategies. The Open Fish Science Journal, 10 (1), 1-11. https://doi.org/10.2174/1874401x01710010001.

[5] Cheruiyot, M., Gathuru, G., \& Koske, J. (2018). Quantity and Trends in Streamflows of the Malewa River Basin, Kenya. Journal of Environmental Science and Engineering, B (7), 1827. https://doi.org/10.17265/2162-5263/2018.01.003.

[6] Becht, R., Odada, E., \& Higgins, S. (2005). Lake Naivasha: Experience and Lessons learned. ILEC, 277-298.

[7] Mwai, M. D. (2011). Effects of Climate Change and Human Activity on Lake Levels in the Kenyan Rift (Case Study Naivasha). University of Nairobi.

[8] Ruhakana, A. (2016). The Estimation of Lake Naivasha Area Changes Using of Hydro-Geospatial Technologies. Rwanda Journal, 1 (II). https://doi.org/10.4314/rj.vli2S.3D.

[9] Moturi, N. F. (2015). A Hydrological Study of the Rising Water Level at Lake Nakuru. University of Nairobi. 
[10] Wanjuhi, D. M. (2016). Assessment of Meteorological Drought Characteristics in North Eastern Counties of Kenya. University of Nairobi, Kenya.

[11] Mondal, A., Kundu, S., \& Mukhopadhyay, A. (2012). Rainfall Trend Analysis by Mann-Kendall Test: a Case Study of North-Eastern part of Cuttack District, Orissa. International Journal of Geology, Earth and Environmental Sciences, 2 (1), 70-78. https://doi.org/ISSN: 2277-2081.

[12] Wambua, R. M. (2016). Drought Assessment and Forecasting using Indices and Artificial Neural Networks for the Upper Tana River Basin, Kenya. Egerton University.

[13] Ustaoglu, B. (2012). Trend analysis of annual mean temperature data using mann-kendall rank correlation test in catalca - kocaeli peninsula, northwest of turkey for the period of 1970-2011. IBAC, 2, 276-287.

[14] Zhang, Y., Cai, W., Chen, Q., Yao, Y., \& Liu, K. (2015). Analysis of changes in precipitation and drought in Aksu River Basin, Northwest China. Advances in Meteorology, 2015 (215840), 15. https://doi.org/10.1155/2015/215840.

[15] Forootan, E. (2019). Analysis of trends of hydrologic and climatic variables. Soil and Water Research, 14 (3), 163-171. https://doi.org/https://doi.org/10.17221/154/2018-SWR.

[16] Gilbert, R. O. (1987). Statistical Methods for Environmental Pollution Monitoring. Van Nostrand Reinhold Company Inc, 1987.
[17] Kyambia, M. M., \& Mutua, B. M. (2014). Analysis of Drought effect on Annual stream flows of River Malewa in the Lake Naivasha Basin, Kenya. Int J Cur Res Rev, 6 (18), 1-6.

[18] Mwenda, N. D. (2019). Trend Detection in Precipitation and River Discharge to Assess Climate Change in the Upper Tana Basin (Issue June). University of Nairobi.

[19] Odongo, V. O. (2016). How climate and land use determine the hydrology of Lake Naivasha Basin [University of Twente]. https://doi.org/10.3990/1.9789036542333.

[20] Reta, G. L. (2011). Groundwater and Lake Water Balance of Lake Naivasha using 3-D Transient Groundwater Model. University of Twente.

[21] Awange, J., Forootan, E., Kusche, J., Kiema, J. B., Omondi, P., Heck, B., Fleming, K., Ohanya, S., \& Goncalves, R., (2013). Understanding the decline of water storage across the Ramser-Lake Naivasha using satellite-based methods. Advances in Water Resources, 60, 7-23. https://doi.org/10.1016/j.advwatres.2013.07.002.

[22] Boitt, M. K. (2016). Impacts of Mau Forest Catchment on the Great Rift Valley Lakes in Kenya. Journal of Geoscience and Environment Protection, 4 (May), 137-145. https://doi.org/10.4236/gep.2016.45014. 